\title{
Automatic Production of Microholes by EDM
}

\author{
Dong-Yea SHEU *, Takahisa Masuzawa ** \\ (Received November 16, 2001) \\ * Department of Mechanical Engineering, National Taipei University of Technology, Taiwan 106 \\ ** Institute of Industrial Science, Center for International Research on MicroMechatronics, University of Tokyo \\ Japan 153-8505
}

\begin{abstract}
Since the development of wire electro-discharge grinding technology (WEDG), micro-EDM has been an excellent method for machining microholes in metals and alloys. However, it is difficult to achieve automatic production of microholes by EDM. This study proposes a new method for fabricating microholes automatically with micro-EDM technology. This new prototyping method, which combines the Twin-WEDG System, Tandem Micro-EDM System and Electrode Supply System, can machine microholes continuously with only one setting up of the spindle. A traditional mechanical pencil was applied in the system for driving the electrode rod. The electrode rod was supplied automatically when the extruded part of the electrode material was worn out. It succeeded in machining 400 microholes continuously without changing the electrode material and spindle. This new system also shows the possibility of mass production of microholes by micro-EDM.
\end{abstract}

Key words : WEDG, Micro-EDM, Microholes, Continuous machining

\section{INTRODUCTION}

Microhole machining has become an important technology in various industrial fields such as fuel injection nozzles, inkjet printer heads, fluid sensors and optical fiber connectors. At present, the major methods of drilling microholes are electrical discharge machining (EDM), mechanical drilling, punching, laser machining and ultrasonic machining. Micro-EDM is an excellent technology for fabricating microholes with high precision. However, it is not only difficult to machine microholes with diameters less than $100 \mu \mathrm{m}$ but also difficult to achieve mass-production of microholes. The holding and supplying of the microelectrode are the main two problems.

In order to achieve the mass production of microholes, a wire electrode with a diameter of 0.1 $0.5 \mathrm{~mm}$ used in a machining device is directly driven by a piezoelectric element to machine microholes ${ }^{1)}{ }^{2)}$. It shows that several microholes can be machined rapidly, but it is difficult to hold the microelectrode with high precision while the diameter of the microelectrode is less than $100 \mu \mathrm{m}$.

Since the development of wire electro discharge grinding (WEDG) technology ${ }^{3}$, the technology was used successfully to fabricate the microelectrode with high precision. There was no need to care about the problem of the bending and holding of the microelectrode. However conventional micro-EDM machines microholes in two stages. First, it needs to prepare a microelectrode, and then uses the microelectrode to machine microholes, which is not very efficient. In order to achieve high performance of microholes machining, we propose a new system, called Automatic Microhole Machining System (AMMS), which can machine the microelectrode and microholes at the same time. AMMS includes the Twin-WEDG System, Tandem Micro-EDM System and Electrode Supply System.

\section{STRUCTURE OF THE SYSTEM}

\subsection{Twin-WEDG system}

The WEDG system is an excellent technology for machining microelectrodes. It has been reported that a microelectrode of $4 \mu \mathrm{m}$ can be machined successfully ${ }^{4)}$. However, the conventional WEDG technology needs two procedures, rough and finish machining. This is time-consuming because a single WEDG unit is busy performing these two procedures in turns. To reduce machining time, we employ two WEDG units (WEDG A and WEDG B) simultaneously, one is for rough machining and the other for finish machining. As shown in Fig. 1, WEDG A works first to machine the microelectrode roughly, when the feed length of the microelectrode exceeds the distance between the two WEDG units, 


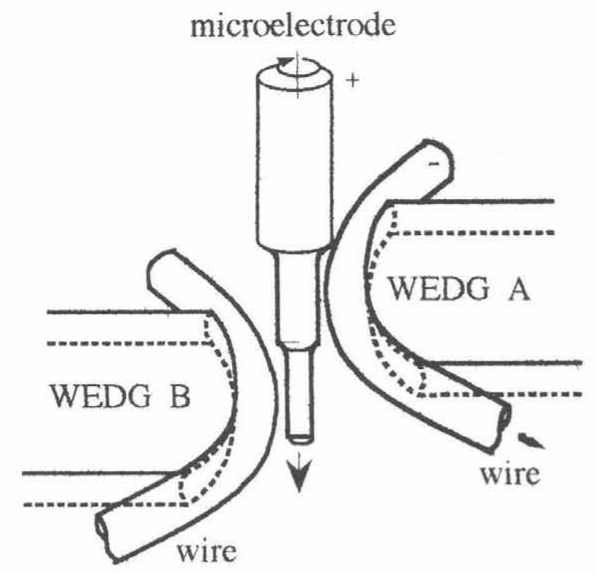

Fig. 1 Principle of Twin-WEDG System

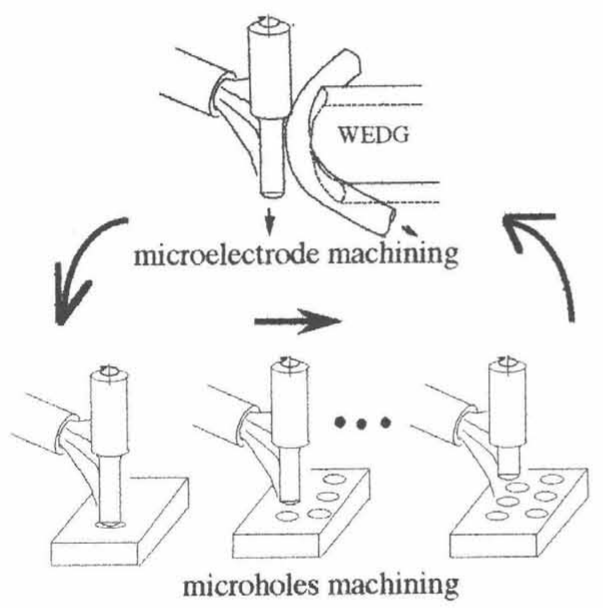

Fig. 2 Conventional procedure of micro-EDM for microholes machining

WEDG B starts to finish the microelectrode while the rough machining at WEDG A unit continues.

The Twin-WEDG system, including two procedures of rough and finish machining, is only for fabricating microelectrodes, microtools and micropins.

\subsection{Tandem Micro-EDM system}

The principle of conventional Micro-EDM technology for microhole machining is shown in Fig. 2. As mentioned above, microhole machining needs to fabricate first a microelectrode. It is also necessary to change the worn electrode rod after microhole machining. In order to achieve automatic microholes machining, we propose a new prototype system called the Tandem Micro-EDM system shown in Fig. 3. As can be seen, Tandem MicroEDM combines the Twin-WEDG system and microhole machining. The system starts to machine microholes when the feed length of the

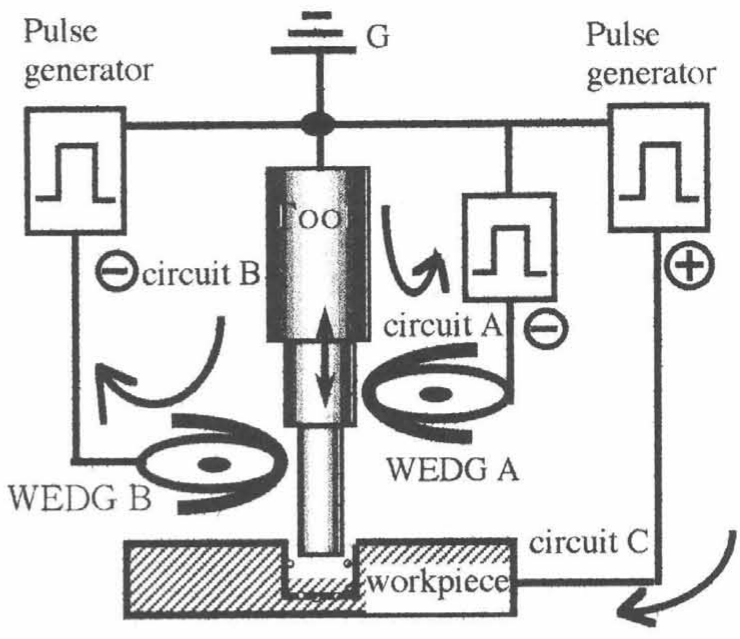

Fig. 3 Principle of Tandem micro-EDM System

microelectrode is about the distance between the workpiece and WEDG units. After microholes machining, the worn length of the microelectrode will be recovered by the Twin-WEDG system. By repeating this process, microholes can be machined continuously until the total length of the electrode material is worn out. The operators need not care about the electrode wear ratio. Different wear ratios are just reflected on the total number of microholes machined in each setting of electrode material.

The target of the Tandem Micro-EDM system is to fabricate microholes. It cannot machine microholes continuously without Twin-WEDG system as shown in Fig. 2 and Fig. 3.

\subsection{Automation of electrode material supply}

Combination of the Twin-WEDG system and Tandem Micro-EDM system is expected to be an effective technology for machining microholes continuously. However, the number of machinable microholes is limited by the length of electrode material extruded out of the electrode holder. In order to machine microholes automatically, a mechanical pencil mechanism is adopted to supply the microelectrode material when the extruded part of the microelectrode material is worn out. A mechanical pencil was inserted inside the spindle. The electrode rod could be fed forward with knock lever pushing the pulley. The whole system configuration is shown in Fig. 4 and Fig. 5. The feed mechanism is the same as a traditional mechanical pencil.

\section{PROTOTYPE SETUP OF DEVICE}




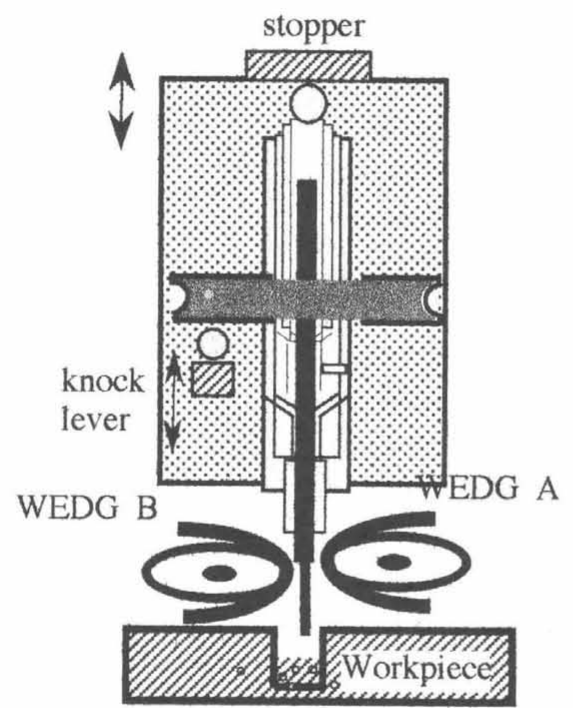

Fig. 4 Automatic microholes machining system

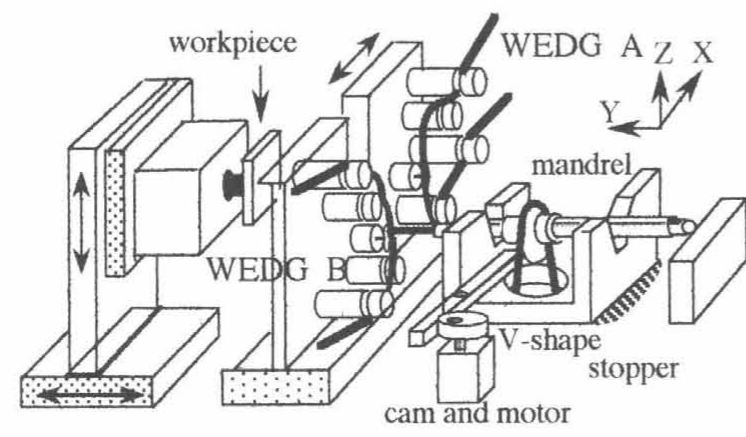

Fig. 5 Setup of automatic production of microholes

\subsection{Outline of device}

Figure 5 shows the setup of the AMMS. The Tandem Micro-EDM system is made up of the Twin-WEDG system for machining microelectrode with rough and finish machining simultaneously. The workpiece is held on the stage behind the WEDG units. The main spindle is set horizontally as shown in Fig. 5. The system includes a V-shaped bearing, a mandrel which holds the electrode material, and a DC motor.

\subsection{Discharge and detect circuit}

The conventional micro-EDM machine has only one set of pulse generator and detecting circuit. However, AMMS combines rough machining, finish machining and hole machining together. It is necessary to set up three sets of pulse generators and detecting circuits because each machining was carried out separately. The detecting circuits check the discharge condition of microelectrode and microholes machining. If any unusual discharge occurs, the spindle will be informed by the computer to resume normal discharge condition.

\subsection{Supply of electrode material}

The conventional micro-EDM machine consists of a mandrel chucking an electrode material simply with a screw. This mandrel can keep accurate rotation as long as the electrode material is not replaced. However, the electrode material must be fed frequently by manual control. Therefore, a special mandrel was designed for the mechanical pencil mechanism. The electrode material can be supplied by knocking the mandrel with a knocklever.

\subsection{Machining condition}

In the experiments described below, oil was used as dielectric. Open voltage was set at $80 \mathrm{~V}$. RC discharge circuits were applied in this system. Discharge capacities were 22000, 220 and $100 \mathrm{pF}$ for rough machining, finishing and microhole machining respectively. The electrode material was tungsten carbide alloy with diameter of $300 \mu \mathrm{m}$. The workpiece was stainless steel.

\section{EXPERIMENT AND RESULTS}

\subsection{Microelectrode machining with Twin-WEDG system}

Figure 6 shows the relationship between the feed length of the electrode and machining time with different diameters of the electrode at the end of rough machining. The finished diameter was fixed at $40 \mu \mathrm{m}$. As shown in the figure, machining speed was fast until the feed length reached $300 \mu \mathrm{m}$ because only rough machining was carried out by WEDG A unit in the initial procedure. When the feed length exceeded the gap distance between the two WEDG units, WEDG B unit started the finish machining and the speed became lower. It can be observed that the larger the diameter after rough machining, the heavier the total removal of the finish machining will be, thus reducing the machining speed. The side view of the microelectrode fabricated by Twin-WEDG system is shown in Fig. 7. The roughness of the two stages machining is obviously different because of the difference in discharge energy. We also can suppose that the two discharge circuits are isolated on Fig. 7.

\subsection{Repeated machining by Tandem Micro-EDM system}

The relations between the feed length of the electrode and machining time are shown in Fig. 8. Microholes machining started at the feed length of 


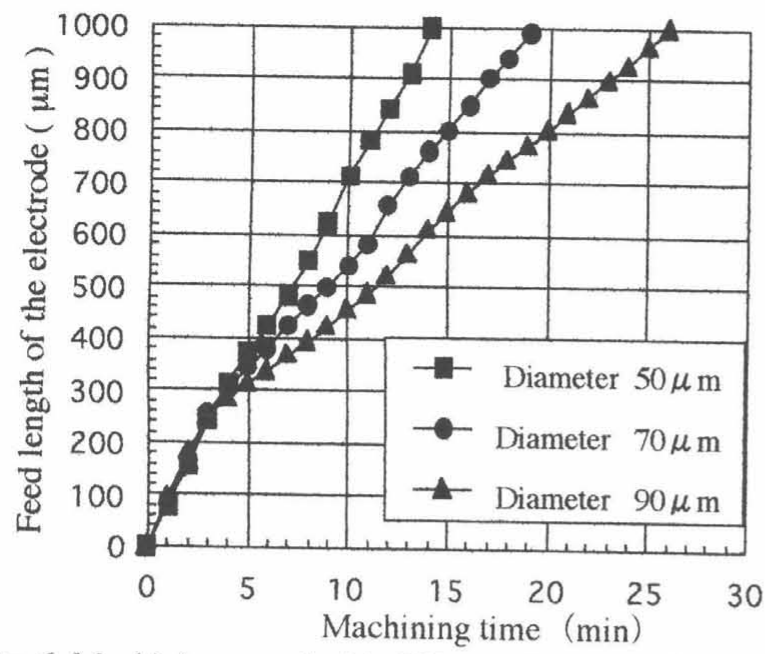

Fig. 6 Machining speed with different diameter of rough machining ( diameter of finish machining: $40 \mu \mathrm{m}$ )

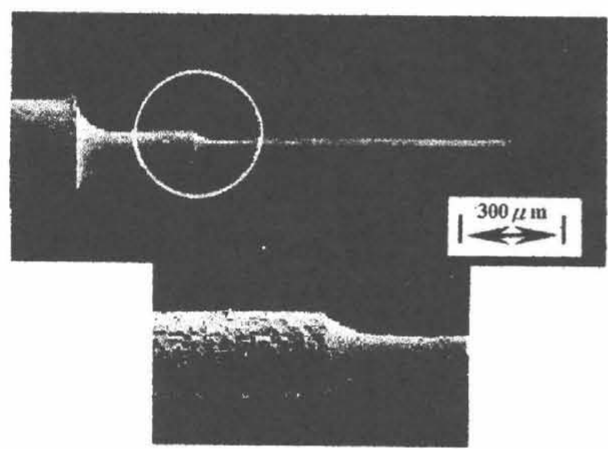

Fig. 7 Finished electrode by Twin-WEDG System ( finish diameter : $40 \mu \mathrm{m}$ )

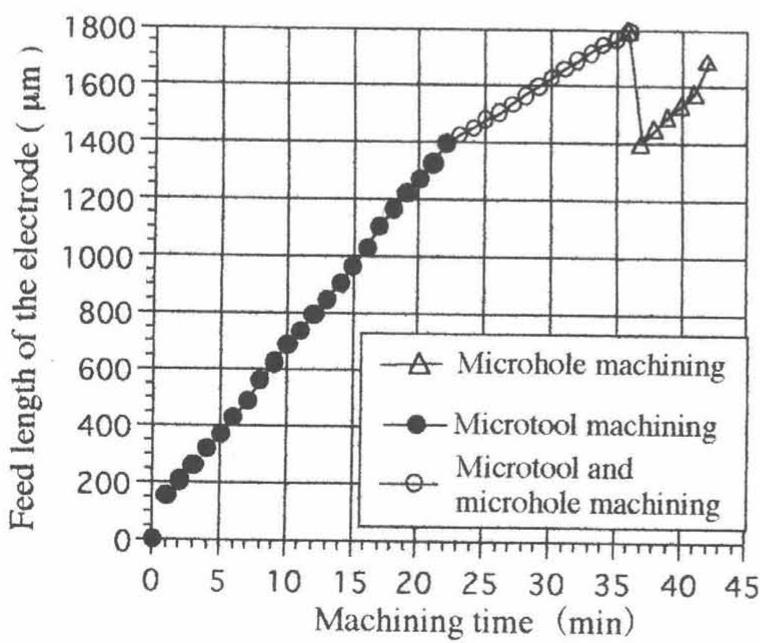

Fig. 8 Microholes machining with Tandem Micro-EDM System

about $1.4 \mathrm{~mm}$ (distance between WEDG units and workpiece). Machining speed decreased because not only the removal volume increased but also discharge conditions became complicated. However, in the machining of the second hole (after $36 \mathrm{~min}$ ),

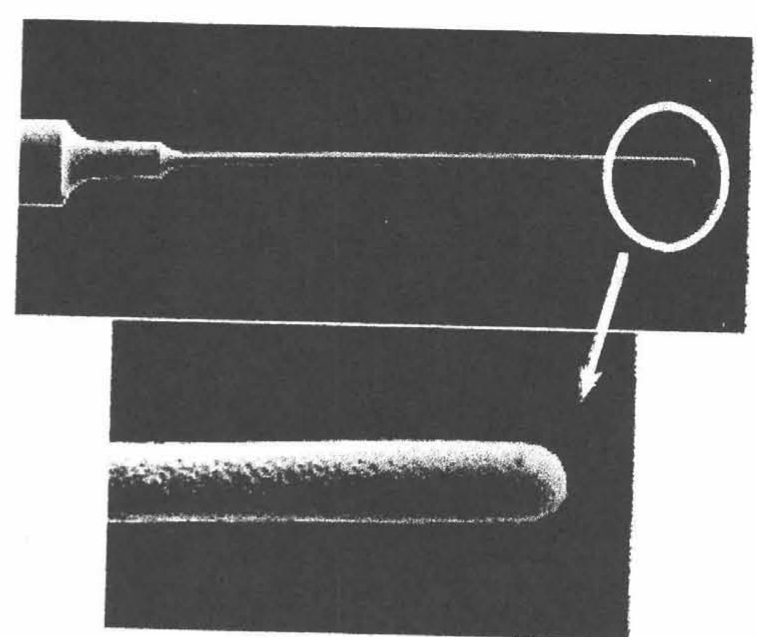

Fig. 9 View of microelectrode after continuous 25-microhole machining

the system performed only hole machining because the part of electrode for this machining had already been fabricated. The part of the electrode worn would be prepared again after machining through the microholes. The microhole machining time for the second one was about 3 minutes, although it took longer to machine the first hole because an electrode $2 \mathrm{~mm}$ long or more need to be fabricated before reaching the workpiece surface.

Tool wear is the main problem in EDM. As the diameter of the microelectrode decreases the wear ratio remarkably increases. Uniform Wear Method ${ }^{5)}$ was developed to machine complex threedimensional cavities successfully. However, it is necessary to consider microelectrode wear including axis direction and radial direction when machining deep microholes ${ }^{6}$. The wear of the microelectrode deteriorates with increasing depth of the micro hole. The view of the microelectrode after machining a total of 25-microholes is shown in Fig. 9. As shown in this figure, the diameter of the microelectrode was uniform after microholes machining. In this study, we are only concerned about the wear ratio in the axis direction of the microelectrode. AMMS can fabricate microholes continuously without considering the wear of the microelectrode because the Twin-WEDG System would shape the microelectrode again.

\subsection{Continuous production of microholes}

A total of 400 microholes were machined as shown in Fig. 10. Figure 11 shows the distribution of the entrance diameter of the microholes and the unevenness of microholes is about 5--6 $\mu \mathrm{m}$. The 


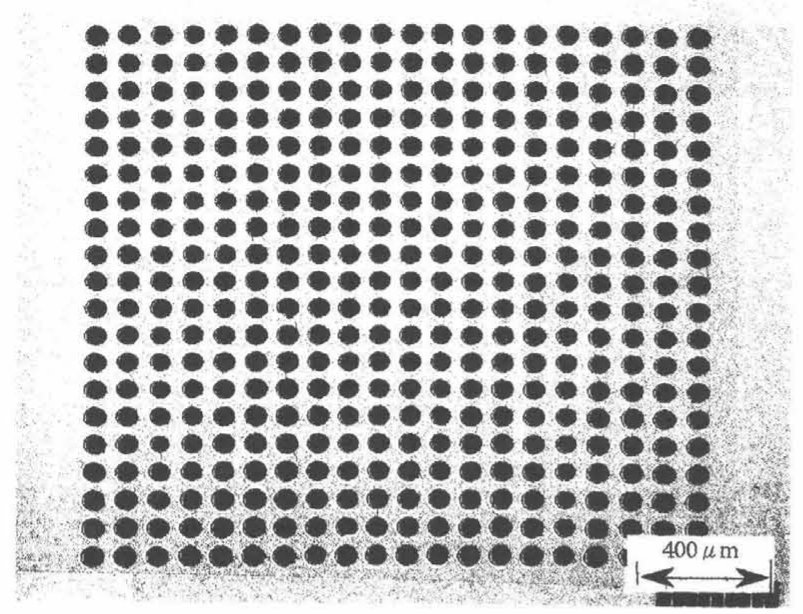

Fig. 10 Top view of the microholes

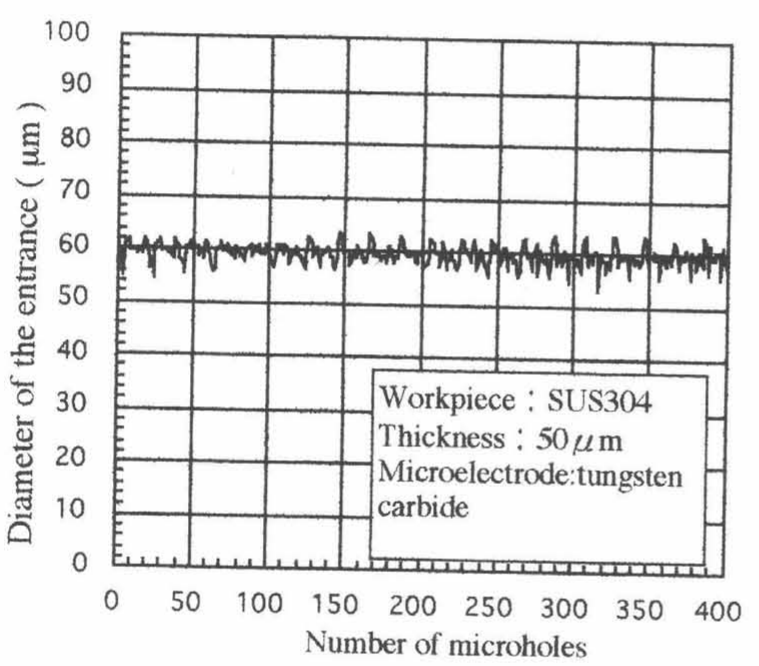

Fig. 11 Distribution of the microholes

main reason for the unevenness is the inaccurate positioning of every movement of the equipment.

\section{CONCLUSION}

We have developed a new prototype machine for continuous production of microholes by EDM. This system includes the Twin-WEDG system, the Tandem Micro-EDM system and automation of supplied electrode material. The results of this research are summarized as follows

(1) Twin-WEDG system is more efficient than conventional single WEDG system to fabricate a microelectrode with rough and finish machining carried out simultaneously.

(2) Simultaneous electrode-making and holemachining could be performed with the prototype setup of the Tandem Micro-EDM system.

(3) The new system, including the Twin-WEDG System, the Tandem Micro-EDM System and Electrode Supply System, can machine microholes automatically with only one setting up of the mandrel.

\section{REFERENCES}

1) Toshiro Higuchi, Katsushi Furutani, Yutaka Yamagata and Kohzo Taketa: Development of Pencil-Size Electro-Discharge Machine. The Japan Society for Precision Engineering (JSPE) Vol.57/5/1991 pp. 166-172

2) Naotake Mohri, Hiromichi Morita and Nagao Saito: Development of An Electrical Discharge Drilling Device by Using a New Method for Direct Drive of Electrode. The Japan Society for Precision Engineering (JSPE) Vol.58/12/1992 pp. 2063-2068

3) T. Masuzawa, M. Fujino, K. Kobayashi: Wire Electro-Discharge Grinding for Micro-machining. Annals of the CIRP, Vol. 34, 1(1985) pp. 431-434

4) K. Egashira, T. Masuzawa, M. Fujino: Microultrasonic Machining by the Application of Workpiece Vibration. Annals of the CIRP, Vol. 48 1/1999, pp. 131-134

5) Z. Yu, T. Masuzawa, M. Fujino: Micro-EDM for Three-Dimentional Cavities - Development of Uniform Wear Method. Annals of CIRP, Vol. 47 1/1998 pp. 169-172

6) D.Y. Sheu, T. Masuzawa, M. Fujino: Machining Deep Microholes by EDM. Proceedings of Internation Conference on Precision Engineering, Taipei, Taiwan (1997) pp. 593-596 